\title{
A Research on Undergraduate Architecture Teaching Approach Based on Integration of Architectural Design and Architectural History Teaching
}

\author{
Wei Li1,2 \\ ${ }^{1}$ School of Architecture and Civil Engineering, Huizhou University, Huizhou, China \\ ${ }^{2}$ State Key Laboratory of Subtropical Building Science, South China University of Technology, Guangzhou, China \\ Email: liwei@hzu.edu.cn
}

How to cite this paper: Li, W. (2018). A Research on Undergraduate Architecture Teaching Approach Based on Integration of Architectural Design and Architectural History Teaching. Creative Education, 9, 1843-1853.

https://doi.org/10.4236/ce.2018.912135

Received: August 6, 2018

Accepted: September 18, 2018

Published: September 21, 2018

Copyright $\odot 2018$ by author and Scientific Research Publishing Inc. This work is licensed under the Creative Commons Attribution International License (CC BY 4.0). http://creativecommons.org/licenses/by/4.0/

\section{Open Access}

\begin{abstract}
Undergraduate Architecture Education comprises these two major aspects: architectural design teaching and architectural history teaching. Due to different philosophies on curriculum, teaching methods, architectural design teaching and architectural history teaching have been long separated, which led to a disjunction between theory and practice, authentic project and scientific research. Under such circumstances, a new teaching approach based on integration and system optimization of architectural design and architectural history is highly demanded, which is of great significance to teaching. The practice of Architecture Undergraduate Program in Huizhou University signifies an innovative path for teaching research and reform. All steps are organized in a systematic way and the mission that we commit to nurturing graduates with application and innovation is fulfilled.
\end{abstract}

\section{Keywords}

Architecture Education, Integration and System Optimization, Architectural Design and Architectural History Teaching

\section{Introduction}

Undergraduate Architecture Education comprises these two major aspects: architectural design teaching and architectural history teaching. However, architectural history teaching focuses on architectural evolution and regional characteristics during different periods. By studying the classical works, students can 
have a better understanding of design methods and philosophies, which helps to enhance their design abilities and creativity. Besides, it assumes an indispensable and irreplaceable role in project management. Due to different philosophies on curriculum, teaching methods, architectural design teaching and architectural history teaching have been long separated, which led to a disjunction between theory and practice, authentic project and scientific research. Under such circumstances, a new teaching approach based on integration and system optimization of architectural design and architectural history is highly demanded, which is of great significance to teaching.

\section{Literature Review}

The Undergraduate Architecture Program in Huizhou University was launched in 2003, following South China University of Technology, Shenzhen University, Guangzhou University and Guangdong University of Technology. Over 13 years' development, it was authorized as Provincial-level Specialty in 2016. Since its launching, we have been committed to nurturing more than 2200 graduates with uniqueness, innovation and application, engaging in engineering and research that has impact and practical value. It has been only 15 years since we were granted Provincial-level Specialty for its remarkable progress, meanwhile, we realize that higher education is undergoing major reforms and that there are still improvements in our curriculum and teaching methods. A fundamental teaching reform, beyond traditional thinking pattern, is badly needed for creative solutions. We strive for a breakthrough in teaching reform by integrating and optimizing architectural design teaching and architectural history teaching, so as to exert an integration effect on talent with application and innovation.

Discussion on architectural design and history teaching reform has been a heated issue since last two decades, however, most scholars simply confine to one of the discipline. Gao (2001) summarized the characteristics and situations of architectural history teaching. Zheng (2004) pointed out several problems in architectural history teaching reform, suggesting that architectural history be taught throughout the five-year program. Fan (2015) proposed design-oriented history teaching model. Li (2016) stated the problems confronted and provided several solutions, such as enhancing interaction between architectural history and architectural design.

Li (2003), professor of Architecture in Huazhong University of Science and Technology, criticized that there was a clear cut between architectural design and history teaching. Besides, he pointed out that architectural design and history, closely related sub-disciplines under architecture, should have been integrated. In his paper entitled $A$ Trial on Integration of Architectural design and Architectural history-Taking Traditional Architecture Image Design as An Example, he elaborated the teaching approach taken by his faculty. He aligned architectural history systematization with architectural design thematization. Architecture program adopts a five-year system. For freshmen, the course $A n$ 
Introduction to Architecture covers a special chapter-Chinese Architecture Past and Present. The Space Construction of Chinese Architecture is added to the course Basis of Architectural design. As for second year students, Course Design on Traditional Architecture Form is assigned in Architectural design, to help students get a better understanding of classical architecture terms. When they move to the third year, having taken Chinese Architectural history, students are required to survey and record ancient architecture. After three years basic training, students are expected to take the course Traditional Architecture Image Design, including research field, research background, image explanation and image expression. This course is the cornerstone for the innovative teaching approach. For the graduates, they need to finish their design project or graduation thesis. Through this model, students are meant to meet the practical needs of society.

Moreover, Xu \& Gu (2013), from Hefei University of Technology, integrated Architectural design and Architectural history through these three stages of teaching and practical training: Typical Cases Analysis, Historical Architecture Summer Studio and Architectural history Special Research, to equip students with desired knowledge, skills and attributes.

Furthermore, Wang, et al. (2012), gave a detailed description of their teaching objectives and teaching plan under the new teaching method. For example, Architectural design for the fourth year students covers a wide range of themes, combining history, culture, ecology and technology; for the graduates, special lectures on Comparisons between Eastern and Western Cultures and Architecture Creation, help students develop their styles.

Last but not least, another practice is from South China University of Agriculture. Qu, et al. (2012) summarized the undergoing reforms on integration of architectural design and architectural history and found out that these trials were feasible and effective. From perspective of teaching research, what our research objectives and whom our creation for determine our teaching methods. How to apply various theories to creation is a process that is worth trying. We organize our themed-based teaching activities, such as Lingnan Museum, Lingnan Culture and Arts Center, protection and utilization of urban villages in Guangzhou, protection and utilization of history architecture in campus and so on, having proved to be a success.

Continuous attention has been paid to the researches and reforms on integration of architectural design and architectural history, we also have made a breakthrough in teaching approach, but at the same time, we have to bear in mind that there is a clear cut between architectural history teaching and architectural design teaching. That is to say, on one hand, architectural history teaching has become part of architectural design teaching, failing to nurture graduates with application and innovation; on the other hand, architectural design teaching fails to provide a platform for the former. Strictly confined to the traditional teaching models, architectural design teaching and architectural history teaching 
in most universities were totally separated in the following three aspects:

First, call for integration on architectural design and architectural history teaching. Though lots of experts have called for integration of architectural design and architectural history teaching, few came out with feasible solutions to applied technique-oriented professionals nurturing.

Second, lack of research on integration and system optimization of architectural design and architectural history teaching. Without a theoretical framework, architectural design and architectural history teaching could not yield satisfactory results.

Third, lack of mature teaching models fit for demonstration and promotion. What's worse, a severe shortage of teaching approach including teaching unit and procedure suitable for universities or colleges directly under province.

In order to solve the above problems, we have been organizing our teaching activities under this framework, i.e. integration and system optimization of architectural design and architectural history teaching, for almost 10 years. A full explanation will be given in the fourth part.

\section{Theoretical Framework}

\subsection{Structuralism}

Positivism is a doctrine that states that the only authentic knowledge is scientific knowledge, and that such knowledge can only come from positive affirmation of theories through strict scientific method, refusing every form of metaphysics while structuralism is a theory of sociology that views elements of society as part of a cohesive, self-supporting structure. Structuralism is the methodology that implies elements of human culture must be understood by way of their relationship to a broader, overarching system or structure. It works to uncover the structures that underlie all the things that humans do, think, perceive, and feel. Alternatively, as summarized by philosopher Simon (2008: pp. 18), structuralism is "the belief that phenomena of human life are not intelligible except through their interrelations. These relations constitute a structure, and behind local variations in the surface phenomena there are constant laws of abstract culture".

French anthropologist Claude Lévi-Strauss was arguably the first such scholar, sparking a widespread interest in structuralism. He produced more linguistically focused writings in which he applied Saussure's distinction between langue and parole in his search for the fundamental structures of the human mind, arguing that the structures that form the "deep grammar" of society originate in the mind and operate in people unconsciously. In his works $A$ World on the Wane (Claude, 2010: pp. 45; Tristes Tropiques French), he pointed out that the universality of human thought processes in an effort to explain the "deep structure" or underlying meaning existing in cultural phenomena. "Structuralism is a set of principles for studying the mental superstructure". It is proposed, then, that a hidden reality exists beneath all cultural expressions. Structuralists aim to understand the underlying meaning involved in human thought as expressed in 
cultural acts.

Jean Piaget, who would better define himself as constructivist, considered cognitive structures development as a differentiation of biological regulations. When his entire theory first became known - the theory in itself being based on structuralism and a cognitivist approach-it was an outstanding and exciting development in regards to the psychological community at that time.

Pierre (1972) was a French theorist who presented his theory of practice on the dichotomical understanding of the relation between agency and structure in a great number of publications, beginning with An Outline of the Theory of Practice (Le Sens Pratique French) in 1972, where he presented the concept of habitus. The key concepts in Bourdieu's work are habitus, field, and capital. The agent is socialized in a "field", an evolving set of roles and relationships in a social domain, where various forms of "capital" such as prestige or financial resources are at stake. As the agent accommodates to his or her roles and relationships in the context of his or her position in the field, the agent internalizes relationships and expectations for operating in that domain. These internalized relationships and habitual expectations and relationships form, over time, the habitus. Bourdieu's work attempts to reconcile structure and agency, as external structures are internalized into the habitus while the actions of the agent externalize interactions between actors into the social relationships in the field. Bourdieu's theory, therefore, is a dialectic between "externalizing the internal", and "internalizing the external". A theory of sociology that views elements of society as part of a cohesive, self-supporting structure. Structuralism is a theoretical paradigm emphasizing that elements of culture must be understood in terms of their relationship to a larger, overarching system or structure. First, a structure determines the position of each element of a whole. Second, every system has a structure. Third, structural laws deal with co-existence rather than change. Fourth, structures are the "real things" that lie beneath the surface or the appearance of meaning (Pierre, 1977: pp. 78-86).

Li (2017) propounded that structuralism is holistic, dialectic, transformative and harmonious and that any particular elements have no absolute meaning or value. A particular element can only be studied as part of a greater structure. Everything makes sense only in relation to something else.

Harvey (2001) stated the collision of different concepts ignites the fire of wisdom, and theoretical innovation is generated from it. Drawn from Structuralism, we integrate architectural history and architectural design teaching and propose a new teaching approach. Guided by Structuralism, upholding holistic, dialectic and transformative thinking, we attempt to integrate architectural history and architectural design teaching, coordinate practice and theory, and connect beginning with advanced level, so as to achieve the goal.

\subsection{Coupled System}

Structuralism is a theory of sociology that views elements of society as part of a 
cohesive, self-supporting structure. Structuralism is the methodology that implies elements of human culture must be understood by way of their relationship to a broader, overarching system or structure. The word "system", in this case, suggests an arrangement of interrelated elements and accounts for the way these elements relate to each other, making a win-win integration. The primary purpose of couplings is to join two pieces of rotating equipment while permitting some degree of misalignment or end movement or both. By careful selection, installation and maintenance of couplings, substantial savings can be made in reduced maintenance costs and downtime. In this context, Coupled System is metaphorized, referring to a more advanced and efficient matching. Under the guidelines of system optimization, we integrate the teaching procedure of architectural design and architectural history, show the evolution mechanism from integration to optimization to innovation as to as make it a model for demonstration.

\section{Practice and Reflection}

Moshi (model), definition given by Modern Chinese dictionary, states that A model is a system that is being used and that people might want to copy in order to achieve similar results. In Mary's view, instructional models, like patterns or blueprints or recipes, present the steps necessary for a desired outcome. The selection of a particular model to use in an instructional design depends on the desired outcome or objective of the instruction. The methods selected for teaching a lesson should depend on what the students are expected to learn as a result of the instruction (Mary et al., 2002: pp. 57).

Guided under the framework of structuralism, teaching model is closely related to teaching structure, procedure and method. An instructional model is a step-by-step procedure that leads to specific learning outcome. The best models have been used extensively and have been found to be effective in achieving specific objectives of instruction. Traditionally, models of teaching are represented by a broad array of teaching systems, each system containing a distinctive philosophical foundation, or theory of learning basis, with related pedagogical methodologies. Since 2003, we have been practicing this instructional model to desired objectives-nurturing students with application and innovation. The model will be presented from the following aspects.

\subsection{Teaching Element}

Guided by structuralism, we take every element of architectural design and architectural history teaching into account and figure out the relations and functions between the part and whole. We integrate these elements systematically and build a network comprising architectural history, architectural design, theory, architecture appreciation and practice. History and theory in architecture are part of the school of architecture curriculum. This section aims to discuss the essentials of school architectural education, including historical know- 
ledge, design abilities, theoretical perception, appreciation and practice.

1) Architectural history. Architectural history is the discipline that records, studies and interprets architecture with the aim to perceive and interpret the past. It studies its forms, purposes, and most importantly its evolution. Fortunately, ancient architecture can easily be observed and recorded. Studying architectural history enables us to understand the society and culture they represent, which is very useful when working as a contemporary architect. In other words, students can study the history of architecture in order to understand how and why each era since the beginning of time formed its own unique style. Architectural history study not only helps students better understand theory and appreciation but also foster their design abilities and skills.

2) Architectural design. Architecture design refers to the actual design and layout of spaces. Architecture encompasses many different elements including construction, design, and the manipulation of light as it relates to shadow. Throughout history, architects have found ways to create functional and practical spaces using any materials that were available.

3) Theories. A far-reaching philosophy of architecture extends beyond even a broadly aesthetics-based assessment, to include considerations of ethics, social and political philosophy, and philosophical reflections on psychology and the behavioral sciences. Philosophy is key component in the analysis of an architect's practice. It is the philosophy of the practice that defines the rationale by which they produce particular solutions to definitive problems. Rationalism, empiricism, structuralism, post-modernism, de-constructivism structuralism and phenomenology are some directions from philosophy influencing architecture.

4) Architectural appreciation. The aesthetics of architecture, by itself, spans traditional issues mooted in philosophy of art, as well as aesthetics of the everyday, and environmental aesthetics. Such traditional issues include the nature of the work; the possibility of classes, kinds, or types in the domain; the character and roles of representation, intentionality, and expression; and the warranted foundations for criticism. The ethics of architecture also addresses traditional issues, including delineation of rights, responsibilities, the good, virtues, and justice in architectural milieus. Aesthetic principles exist in any building design and cannot be separated from the design, therefore making them inherent. Aesthetics, economics and functions must be seamlessly integrated in order to achieve a successful architectural solution.

5) Professional practice. Architecture school curriculum encourages students to undertake professional practice outside classroom. A professional architect is responsible for much more than design. Education should enable students to fulfill the specific knowledge needs of interns and emerging professionals.

\subsection{Teaching Procedure}

In order to build an open, multilayer, comprehensive and collaborative platform 
for architecture education, instructional model centered on the integration of architectural design and architectural history, together with phase-advancing, interdisciplinary and comprehensive system, is constructed meet our missions and goals.

1) Integration of various kinds of instruction, such as classroom instruction, practicum activities, competitions.

2) Encouraging active learning, the use of innovative teaching approaches and technology, and promoting the adoption of integration and system optimization of architectural history and design instructional model. From simple to complex, teaching content is organized in spiral principle. Three themes are carried through the undergraduate program. Appreciation on classical historic architecture focusing on space, function and form is for freshmen and sophomores. Case study on classical architecture design methods discussing environment, technology and anthropology in a broader context is for the third students. Architectural thoughts and practice illustrates how the architectural thoughts and the design process has developed from antiquity to the present day, which provides students with an insightful look at the principles of design. Through the four-year program, students are expected to enhance their basic design skills, hands on competence and creativity.

3) Aligns with the University Vision and Mission, developing students' knowledge, communication skills and professional competence, promotes critical and innovation thinking and problem-solving abilities, embeds practical experience, and is informed and underpinned by research and competition. Encourage students to participate actively in research and competition. To ensure that mandatory practical, research, work-integrated and service learning experience is included within each program, and that each program curriculum is fit for purpose, relevant, academically validated to international standards.

4) To advance our program as a leading major in Huizhou and nearby, the local unique resources, such as Lingnan Uniqueness and Dongjiang Rivers Uniqueness, should be made full use and offer opportunities to enhance students' innovation and application.

\subsection{Teaching Methodology}

The term teaching methodology refers to the general principles, pedagogy and management strategies used for classroom instruction. It assumes a core role and has a far-more reaching influence than content in classroom instruction.

I will give a detailed description of the undergraduate architecture teaching approach based on integration of architectural design and architectural history teaching taking graduation design project as an example (Seen Figure 1).

Graduation thesis project helps to nurture and inspire design-minded learners. Our philosophy is rooted in design thinking, and we focus on preparation for practice and project-based learning through our bachelor's degree programs. Due to the limitations of project-based thesis design, we adjusted the instruction 


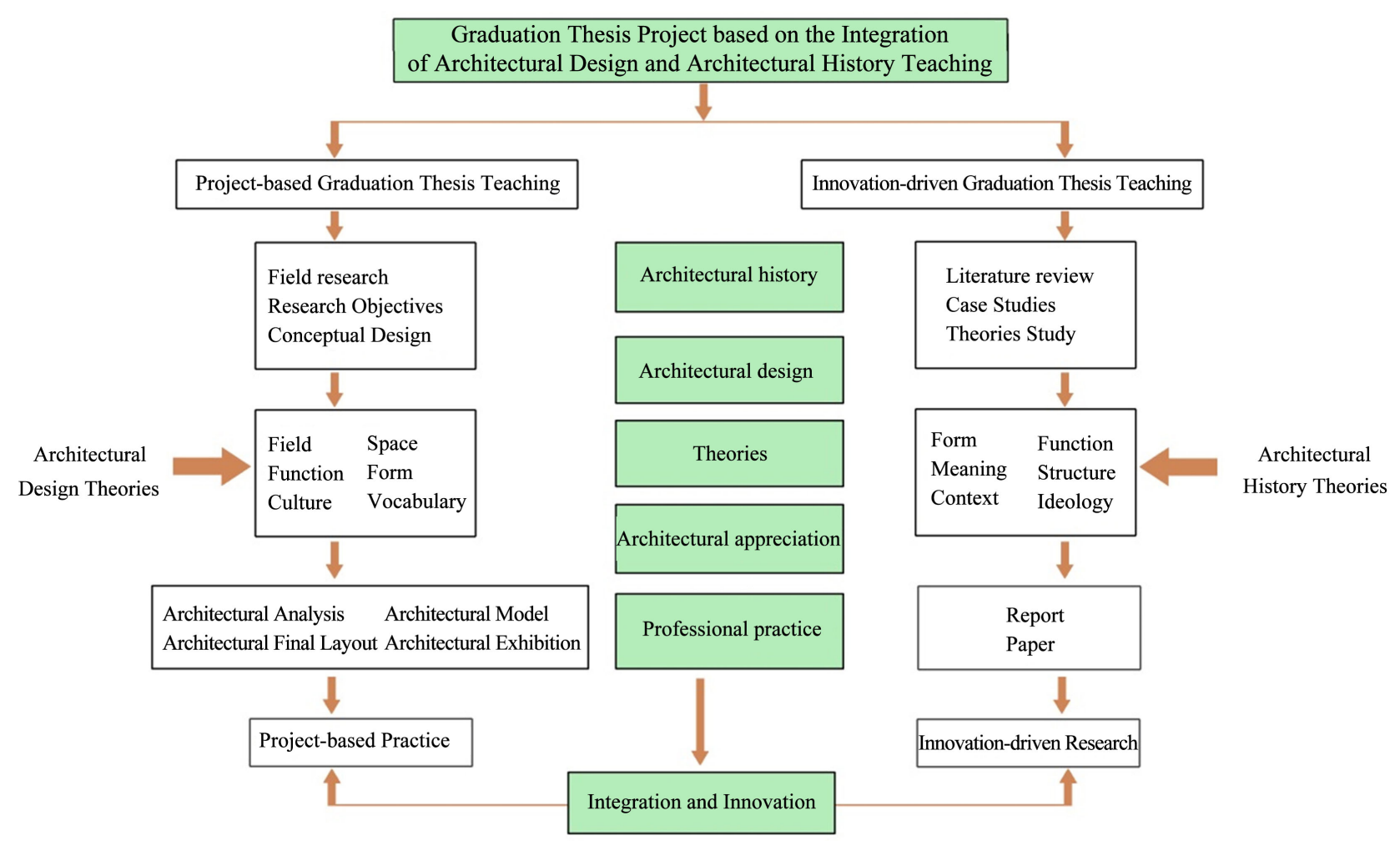

Figure 1. Graduation thesis project based on the integration of architectural design and architectural history teaching.

models by integrating project-based design and innovative research program. Project-based thesis design requires an authentic selection of project, covering a wide range of fields such as urban design, urban planning, historic architecture protection and restoration. On one hand, project-based design has practical values, closely related to social needs, preparing students for the vast body of knowledge required to effectively manage architectural projects and practice. On the other hand, it is strictly confined to practice and subjected to the requirements of Party A, which leads to an inconsistency between teaching and project management. We attempted to solve the problem by making adjustments to authentic projects and integrating desired research, with the aims of nurturing students with application and innovation. Only in this way can students get a whole picture of architecture education with innovative and critical thinking. By means of field research and literature review, students are expected to foster critical thinking abilities and creative problem-solving skills.

The instructional model presented in this paper has proved to be a success and we have been granted Provincial-level Specialty since 2016. The architecture program has forged distinctive characteristics with more than 2200 talents. Besides, according to a survey conducted by Iresearch-China Alumni Association, the architecture major has ranked NO.5 in Guangdong province since 2017². Students are encouraged to participate various design competitions, such as Vertical Farming International College Architectural Design Competition, the 1http://www.cuaa.net/paihang/news/news.jsp?information_id=132833 
Challenge Cup, National University Student Social Practice and Science Contest on Energy Saving \& Emission Reduction.

\section{Conclusion}

We strive for a breakthrough in teaching reform by integrating and optimizing architectural design teaching and architectural history teaching, so as to exert an integration effect on talent with application and innovation. Due to different philosophies on curriculum, teaching methods, architectural design teaching and architectural history teaching have been long separated, which led to a disjunction between theory and practice, authentic project and scientific research. Under such circumstances, a new teaching approach based on integration and system optimization of architectural design and architectural history is highly demanded, which is of great significance to teaching. The practice of Architecture Undergraduate Program in Huizhou University signifies an innovative path for teaching research and reform. All steps are organized in a systematic way and the mission that we commit to nurturing graduates with application and innovation is fulfilled.

\section{Acknowledgements}

The author would like to express heartfelt thanks to Guangdong Higher Education Teaching Reform Project and Guangdong Teaching Quality and Teaching Reform Project under Construction for providing financial support. Besides, I appreciate the support given by State Key Laboratory of Subtropical Building Science, South China University of Technology, under the program "Integrality" on He Jingtang's Architecture Theory of Two Concepts and Three Features (2015ZB08).

\section{Conflicts of Interest}

The author declares no conflicts of interest regarding the publication of this paper.

\section{References}

Claude, L. C. (2010). A World on the Wane (pp. 45). Montana: Kessinger Publishing LLC.

Fan, X. G. (2015). Design-Oriented History Teaching: Discussion on Teaching of Relatively Independent Chapters of Ancient Architecture History. Collection of 2015 Architecture History Teaching Seminar (pp. 225-228). National Academy of Architecture Discipline Professional Guidance Committee.

Gao, J. H. (2001). Study for the Characteristics and Situations of Architecture History-Ideas from "2000 Chinese Architecture History Education Meeting". Huazhong Architecture, 3, 85-86.

Harvey, D. (2001). Spaces of Capital: Towards a Critical Geography (pp. 9). Edinburgh: Edinburgh University Press.

Li, R. M. (2016). Problems of Architectural History Teaching and their Solutions. Construction Materials \& Decoration, 1, 176-177.

Li, W. (2017). Concept Reconstruction, Discourse Construction and Structuring: Innova- 
tive Research of He Jingtang's Architecture Theory of Two Concepts and Three Features. Journal of Huizhou University (Natural Science Edition), 3, 96-101.

Li, X. F. (2003). A Trial on Integration of Architectural Design and Architectural History-Taking Traditional Architecture Image Design as An Example. Architectural Education, 12, 58-59.

Mary, A. G., Thomas H. E., et al. (2002). Instruction: A Models Approach (4th ed., pp. 57). Boston: Allyn and Bacon.

Pierre, B. (1977). An Outline of the Theory of Practice (pp. 78-86). Cambridge: Cambridge University Press.

Qu, H. F., Chen, F. H., et al. (2012). Bridging the Past and the Modern-An Integration of Architectural History and Architectural Design Course. Journal of Hunan University of Science and Engineering, 1, 59-61.

Simon, B. (2008). Oxford Dictionary of Philosophy (2nd ed. revised, pp. 18). Oxford: Oxford University Press.

Wang, Zh. N., Wu, X. J., et al. (2012). On the Methods of Teaching Integration of Architectural Design and Architectural History. Value Engineering, 9, 272.

$\mathrm{Xu}$, Zh., \& Gu, D. Zh. (2013). An Innovative Study on Architectural History Teaching Model for Excellent Engineers. Journal of Southeast University (Philosophy and Social Science Edition), S2, 149-152.

Zheng, L. P. (2004). Several Problems in Teaching Reform of the Architecture History. Architectural Education, 5, 148-149. 